\title{
TeCnologia PAR DE Cobre - ITED 3.
}

\section{PARA ALÉM DA TRANSMISSÃO DE VOZ E DADOS.}

\section{Preâmbulo}

A Autoridade Nacional de Comunicações (ANACOM) aprovou em 5 de setembro de 2014, a 3.a edição do Manual ITED Prescrições e Especificações Técnicas das Infraestruturas de Telecomunicações em Edifícios, bem como a sua entrada em vigor a 8 de setembro do mesmo ano. Até ao final do ano de 2014 ocorre um período transitário sendo considerados válidos os projetos efetuados de acordo com as anteriores prescrições e especificações técnicas, a 2. edição do Manual ITED. Este novo Manual, longe de ser uma rutura com a anterior edição, possui um carácter mais ajustado à realidade socioeconómica atual em Portugal. Com efeito, há uma clara preocupação para redução de gastos mantendo, ainda assim, indicadores mínimos para o edificado novo ou a reconstruir.

Há uns anos que Portugal abrandou o ritmo de construção, um dos anteriores pilares aceleradores da nossa economia. Com o abrandamento da construção abrem-se, porém, novas oportunidades e desafio como é o caso da reestruturação. As cidades têm vindo a assumir uma importância cada vez maior nos países e própria humanidade. Num artigo publicado pelo Eng. António Vidigal na Revista Energia e Futuro n.1 em Fevereiro de 2011, "Smart Grids - As redes de distribuição de energia do futuro", sustenta que em 2030, duas em cada três pessoas habitem no espaço urbano e que se em 1950 existiam 83 cidades com mais de 1 milhão de habitantes, nos nossos dias existem 468, sendo já 25 o número de cidades mundiais com mais de 10 milhões de pessoas.

Assim, a reconstrução, em particular a requalificação do edificado e das suas respetivas infraestruturas serão de extrema importância para a economia das empresas de construção, telecomunicações e instalações elétricas e, consequentemente, para Portugal.
Este artigo aborda de uma forma sucinta, mas objetiva a problemática da utilização de cabos de par de cobre nas infraestruturas de telecomunicações. Problemática pelas fragilidades que podem representar não só para a qualidade da transmissão de dados, como também para o próprio património. Há claramente, uma diferença entre cabos em cobre e cabos com "banho" de cobre. Estas diferenças estendem-se muito além do fator económico, sempre alvo de preocupação e ponderação. Os profissionais deste setor, projetistas, instaladores, fabricantes e fornecedores têm o dever e obrigação de estarem devidamente informados acerca das vantagens, desvantagens, convenientes e inconvenientes da utilização das soluções tecnologicamente disponíveis. Convém realçar que o que é "permitido", em termos legais, estabelece um conjunto de requisitos mínimos. Cabe a "todos nós", com o devido enquadramento regulamentar, zelar pela melhor solução técnica que garanta as pretensões e níveis de conforto do utilizador final mas, concomitantemente, garanta a segurança de bens e pessoas.

\section{Introdução}

A secção 3 da 3a edição do Manual ITED estabelece que as redes de cabos (ou simplesmente cablagem) caracterizam-se como o elemento das ITED que permite o transporte e distribuição dos sinais de telecomunicações nos edifícios nas três tecnologias de cabos definidas para o transporte físico da informação: cabos de par de cobre, cabo coaxial e fibra ótica. No que respeita à tecnologia de par de cobre os seus requisitos e caraterísticas mínimas estão também endereçadas nessa terceira seção.

Uma questão importante que se impõem é: Há diferenças entre cabos par de cobre maciços (em cobre) e cabos em alumínio cobreado? Antes de se responder a essa questão convém identificar o que são os cabos em alumínio cobreados. 
O cabos em alumínio cobreado (cabos de alumínio com "banho" de cobre), designados por Copper Clad Aluminum (CCA) é um condutor de alumínio com um revestimento de cobre fino. Este processo e realizado através do revestimento de um fio de alumínio de uma camada de cobre em toda a sua extensão. O alumínio é esticado através de uma série de rolos a fim de reduzir o seu diâmetro, que pode alcançar os 0,1 milímetros, o mesmo que a espessura de um cabelo humano. O alumínio é um metal abundante na natureza, barato, mas menos condutor que o cobre. A utilização dos cabos do tipo CCA, com a reduz substancial do teor de cobre reduz claramente o custo de produção do cabo. Assim, como o próprio nome indica, os condutores CCA substituem uma grande proporção de cobre no centro do condutor por alumínio, obtendo um produto mais leve e mais económico. Esta alteração nem sempre é percetível pelo instalador ou pelo cliente final.

Com efeito, o cabo do tipo CCA apresenta menor peso quando comparado com o cabo de cobre sólido, principalmente. Pelo facto do cabo do tipo CCA ser significativamente mais leve do que o cobre, em algumas aplicações pode oferecer vantagens na contenção dos cabos e no seu manuseio. $O$ custo do alumínio é cerca de um terço do preço do cobre e, portanto, oferece maiores contrapartidas financeiras. O roubo é também menos provável com os valores de "sucata" em grande parte reduzida.

O Communications Cable and Connectivity Association (CCCA), com sede em Washington, DC, USA, (disponível online em: http://cccassoc.org/), descobriu que certos cabos de comunicações de quatro pares não blindados fabricados em alumínio cobreado estão incorretamente marcados e etiquetados. Estes cabos estão a ser vendidos como cabos de "categoria" e com segurança ao fogo, mas por definição não cumprem os códigos e normas previstos para este tipo de cabos tal como estão etiquetados. Em função disso, quem instala ou fabrica estes cabos UTP (Unshielded Twisted Pair Par Trançado sem Blindagem) de quatro pares de alumínio cobreados impropriamente etiquetados podem ser expostos a procedimento jurídico.
O mercado de telecomunicações de cablagem estruturada hoje em dia é muito competitivo, o que encoraja alguns utilizadores finais a procurar cabos mais baratos para os seus requisitos de cablagem estruturada. Uma forma que alguns fabricantes poderiam utilizar para reduzir o custo deste tipo de produtos é não utilizar cobre maciço, mas sim condutores de alumínio revestidos com cobre (CCA).

Embora em algumas aplicações não relacionadas com transmissão de dados os condutores CCA possam ser utilizados, no sector da cablagem estruturada os cabos de condutores com cobre maciço são essenciais para garantir o rendimento e a conformidade com as normas.

Como todos os cabos que contêm CCA não estão em conformidade com as normas e possivelmente, poderiam ser falsificados, podem apresentar graves problemas para o rendimento da rede.

\section{Normas}

Há três conjuntos principais genéricos de normas de cablagem estruturada. ISO/IEC 11801 a nível internacional, EN 50173-1 na Europa e a ANSI/TIA 568-C na América do Norte (ver Tabela 1)

Dentro deste conjunto de normas existem normas que definem em detalhe os requisitos dos cabos. Na América do Norte, os cabos para utilização em sistemas de cablagem estruturada estão definidos na norma ANSI/TIA 568-C.2, na Europa na norma 50288 e internacionalmente na parte correspondente da norma IEC 61156.

Todas estas normas especificam que os condutores do cabo devem ser em cobre maciço, inclusive se os condutores estão trançados para aplicações flexíveis, tais como cordões de ligação. Os condutores CCA não são permitidos em nenhuma destas normas.

Qualquer fabricante que utilize CCA e declare conformidade com estas normas ou diga possuir certificados de laboratórios independentes para os seus cabos, está prestando falsas declarações pelo que deve ser evitado. 
Tabela 1. Algumas normas e respetivos desempenhos especificados

\begin{tabular}{|c|c|c|c|}
\hline Largura de Banda do Sistema & $\begin{array}{c}\text { Internacional } \\
\text { ISO 11801 }\end{array}$ & $\begin{array}{c}\text { União Europeia } \\
\text { EN 50173 }\end{array}$ & $\begin{array}{c}\text { América do Norte } \\
\text { TIA/EIA - 568 }\end{array}$ \\
\hline $100 \mathrm{MHz}$ & Classe D & Classe D & Cat. 5e \\
\hline $250 \mathrm{MHz}$ & Classe E & Classe E & Cat. 6 \\
\hline $500 \mathrm{MHz}$ & Classe EA & Classe EA & Cat. 6 Aumentada \\
\hline $600 \mathrm{MHz}$ & Classe F & Classe F & Cat. 7 \\
\hline $1000 \mathrm{MHz}$ & Classe FA & Classe FA & Cat. 7 Aumentada \\
\hline
\end{tabular}

\section{Rendimento}

Tal como acontece com as normas nacionais e internacionais, os cabos que contêm CCA também ficam curtos no rendimento elétrico e na instalação.

Crê-se, erradamente, que os condutores CCA têm propriedades elétricas equivalentes aos condutores de cobre maciço. Como os condutores CCA têm uma capa de cobre no exterior, isto significa que o rendimento nas frequências mais altas pode ser similar, mas em frequências mais baixas e para os parâmetros de corrente DC, o rendimento degradase.

Comparativa ISO 11801 Classe D Ligação Permanente de CCA e condutores de cobre maciço.

O alumínio tem uma resistência elétrica muito superior ao cobre. Isto significa que os cabos com condutores CCA falham o teste de Ligação Permanente, especialmente para longitudes de mais de 80 metros.

Os condutores CCA também têm uma atenuação mais alta que o cobre, o que terá um efeito notável em canais de maior longitude e criará problemas de rede aos utilizadores, conforme representado na Tabela 2 . O alumínio tem um rendimento mecânico inferior ao cobre, pelo que os utilizadores podem verificar que os cabos CCA se danificam mais facilmente que os cabos de cobre maciço.
Isto tem um efeito sobre a instalação onde os cabos CCA são suscetíveis a um maior estiramento e em alguns casos os condutores podem partir-se.

Os cabos de par trançado com CCA também têm menos tolerância a raios de curvatura. Outros problemas também podem ser verificados durante a terminação dentro do conector tipo IDC, onde a oxidação do alumínio reduz a resistência do condutor e pode conduzir a uma má terminação e com o tempo o condutor CCA pode quebrar-se facilmente causando quebra da ligação.

\section{Power over Ethernet (PoE)}

A aplicação de corrente elétrica num condutor liberta energia térmica. Em relação aos cabos e componentes Ethernet, esse efeito de aquecimento é motivo de preocupação devido ao aumento da atenuação, que tem um efeito limitativo na longitude da ligação.

Esta preocupação intensifica-se para os cabos onde a resistência elétrica é superior à dos cabos normalizados, como são os cabos CCA.

Com a crescente utilização de equipamentos que suportam esta tecnologia a utilização deste tipo de cabos para transporte de dados/alimentação necessita de uma ponderação séria e segura por parte dos projetistas e instaladores.

Tabela 2. Valores de ensaio dos cabos do tipo CCA vs UTP Cat.5e

\begin{tabular}{|c|}
\hline Amostra de Cabo \\
\hline Cabo UTP Cat.5e de um fabricante no mercado \\
\hline CCA Amostra \#1 \\
\hline CCA Amostra \#2 \\
\hline CCA Amostra \#3
\end{tabular}

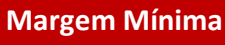

9.7

4.4

$-2.2$

5.0
Margem Mínima NEXT (dB)

11.1

10.0

8.0

8.5

\section{Resistência (Ohm)}

3.5

5.9

5.8

5.5 


\section{Conclusões}

Contrariamente ao que se possa imaginar, e quando comparado com as tecnologias de cabo coaxial e fibra ótica, a especificação da cablagem de par de cobre não é uma mera e trivial escolha. A decisão sobre o cumprimento de níveis de qualidade de transmissão, aliados à segurança das instalações e utilizadores não deve ser relegada para um plano inferior. A escolha por produtos de qualidade e que confiram segurança às instalações deve ser, necessariamente, alvo de prioridade. A realidade tem dado mostras que os fabricantes de topo continuarão a utilizar somente condutores de cobre maciço de alta qualidade em todos os seus sistemas de cablagem.
Não se recomenda a utilização de cabos CCA em nenhum local de uma rede estruturada ou de telecomunicações. De referir, por exemplo, que na industria automóvel a utilização deste tipo de cablagem nos sistemas de áudio trouxeram grandes dissabores pelos perigos de incêndio eminentes.

O Manual ITED 3ạ. Edição faz referência na sua tabela 3.1.1 à norma europeia EN 50288-5-1 no que diz respeito ao fabrico dos cabos de cobre, esta norma diz claramente que "Construções com "copper clad" não cumprem os requisitos", pelo que a ANACOM não poderá, em circunstância alguma, permitir a utilização deste tipo de cabos.

\section{CURIOSIDADE - REDE DE DISTRIBUIÇão MT/BT CHICAGO - EUA}

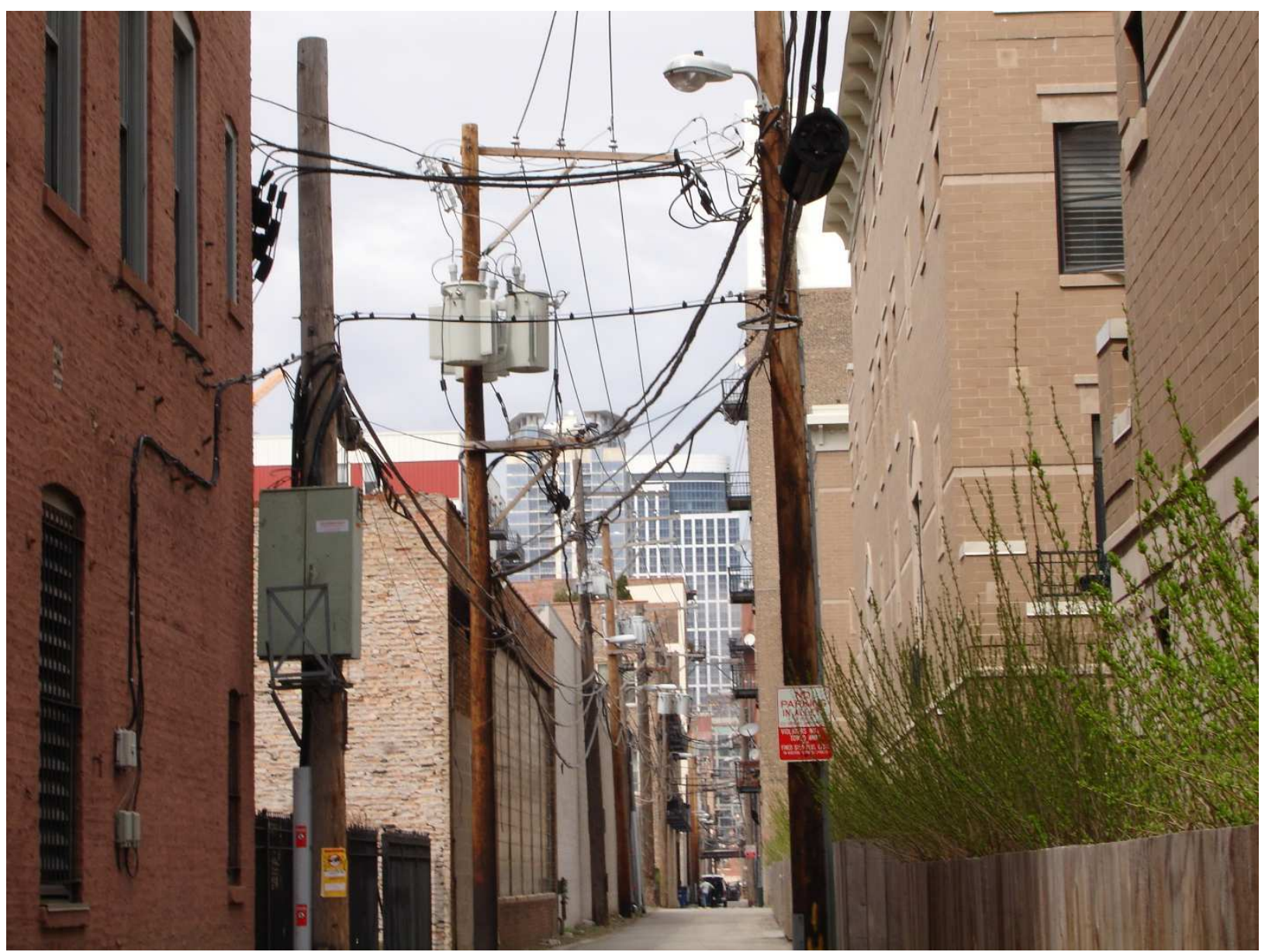

